\title{
Late embryonic losses in supplemented grazing lactating dairy cows: Risk factors and reproductive performance
}

\author{
Luis E. Quintero Rodríguez, ${ }^{1,2}$ Ramiro Rearte, ${ }^{2,3}$ Germán Domínguez, ${ }^{4}$ R. Luzbel de la Sota, ${ }^{1,2}$ \\ Laura V. Madoz, ${ }^{1,2 *}$ and Mauricio J. Giuliodori ${ }^{5 *} \dagger$ \\ ${ }^{1}$ Cátedra y Servicio de Reproducción Animal, Facultad de Ciencias Veterinarias, Universidad Nacional de La Plata, La Plata, \\ B1900AVW Argentina \\ ${ }^{2}$ Consejo Nacional de Investigaciones Científicas y Tecnológicas (CONICET), Ciudad Autónoma de Buenos Aires, C1033AAJ, Argentina \\ ${ }^{3}$ Cátedra de Epidemiología y Salud Pública, Facultad de Ciencias Veterinarias, Universidad Nacional de La Plata, La Plata, B1900AVW Argentina \\ ${ }^{4}$ Actividad Privada, Santa Fe, Venado Tuerto, 2600, Argentina \\ ${ }^{5}$ Cátedra de Fisiología, Facultad de Ciencias Veterinarias, Universidad Nacional de La Plata, La Plata, B1900AVW Argentina
}

\section{ABSTRACT}

The main objective of this study was to evaluate the risk factors for late embryonic loss (LEL) in supplemented grazing dairy cows. Additional objectives were to assess the incidence of LEL and its association with the reproductive performance of cows. A data set containing productive, reproductive, and health records of 13,551 lactations was used. A retrospective case-control study involving 631 cows with LEL (cases) and 2,524 controls (4 controls per case within each study year) was run. A case of LEL was defined when the embryo had no heartbeat or there was evidence of detached membranes or floating structures including embryo remnants by ultrasonography (US) at 28 to $42 \mathrm{~d}$ postartificial insemination (AI), whereas a non-case was defined as a cow diagnosed with positive pregnancy by US 28 to $42 \mathrm{~d}$ post-AI and reconfirmed as pregnant 90 $\pm 7 \mathrm{~d}$ post-AI. Four controls per case were randomly selected from the non-cases with a temporal matching criterion $( \pm 3 \mathrm{~d}$ around the date of the fecundating AI of the case). Multivariable logistic models were offered with the following predictors: year of LEL (2011 through 2015), season of LEL (summer vs. fall vs. winter vs. spring), parity ( 1 vs. 2 vs. $\geq 3$ ), uterine disease (UD), non-uterine disease (NUD), body condition score at parturition, body condition score at 28 to 42 d post-AI (BCS-LEL), days in milk (DIM), and daily milk yield (MY). Statistical significance was set at $P$ $<0.05$ and a tendency was set at $P \leq 0.10$. We found that $4.7,22$, and $23 \%$ of cows had LEL, UD, and NUD, respectively. Cases tended to have higher daily MY than controls (32.5 vs. $31.8 \mathrm{~kg}$ ); also, cases had much

Received December 10, 2018.

Accepted May 30, 2019.

*These authors contributed equally to this work.

†Corresponding author: mauriciog@fcv.unlp.edu.ar longer calving to pregnancy interval (226 vs. 118 d), lower hazard of pregnancy [hazard ratio $=0.39,95 \%$ confidence interval $(\mathrm{CI})=0.35-0.43]$, and higher odds for non-pregnancy [odds ratio $(\mathrm{OR})=2.89,95 \% \mathrm{CI}=$ $2.37-3.54]$ than controls. We found that the odds for LEL increased with parity number $(\mathrm{OR}=2.48,95 \%$ CI $=1.99-3.08$ for parity $\geq 3$ ) and with BCS-LEL $<2.50$ $(\mathrm{OR}=1.81,95 \% \mathrm{CI}=1.33-2.47)$. Conversely, the odds for LEL decreased with BCS-LEL $>3.00(\mathrm{OR}=0.70$, $95 \% \mathrm{CI}=0.53-0.91)$. The odds for LEL increased with $\mathrm{UD}(\mathrm{OR}=1.23,95 \% \mathrm{CI}=1.01-1.49), \mathrm{NUD}(\mathrm{OR}=$ $1.24,95 \% \mathrm{CI}=1.01-1.54), \mathrm{DIM}(\mathrm{OR}=1.03,95 \% \mathrm{CI}$ $=1.00-1.05)$, and daily $\mathrm{MY}(\mathrm{OR}=1.14,95 \% \mathrm{CI}=$ 1.04-1.25) in univariable models only. Finally, the odds for LEL were not associated with year, season, DIM, and body condition score at parturition. In conclusion, LEL is associated with extended calving to pregnancy interval, and among its risk factors are parity number and BCS-LEL.

Key words: late embryonic loss, reproductive performance, clinical disease, milk yield, grazing dairy cow

\section{INTRODUCTION}

The establishment and maintenance of pregnancy in lactating dairy cows is the paramount objective of dairy farms in order to remain profitable over time (De Vries, 2006). Several factors can affect reproduction in dairy cows, such as extended postpartum anovulatory period, poor estrus detection, low pregnancy per insemination, and high pregnancy loss (Santos et al., 2009). Pregnancy can be lost at any time during entire gestation, and it is classified as embryonic loss at $\leq 42$ $\mathrm{d}$ post-AI or as fetal loss at $\geq 43 \mathrm{~d}$ post-AI (Evans and Walsh, 2011). Most of the losses occur during the first $60 \mathrm{~d}$ of gestation at embryonic or early fetal stages (Wiltbank et al., 2016). Early embryonic loss (0-24 d 
post-AI) detection is not practical under commercial conditions because it requires the measurement of pregnancy-associated proteins (Engelke et al., 2015). Conversely, late embryonic loss (LEL; $25-42$ d post-AI) becomes easier to diagnose due to the routine use of ultrasound examination for early pregnancy diagnosis (around $30 \mathrm{~d}$ post-AI). The literature about pregnancy loss, including LEL and early fetal loss (i.e., from about 25 up to $84 \mathrm{~d}$ post-AI) reported that the proportion of cows that lose their pregnancies varies from 7.2 to $29 \%$ (Silke et al., 2002; Diskin et al., 2006; Gábor et al., 2008; Santos et al., 2009; Abdalla et al., 2017).

Among the proposed risk factors for pregnancy loss (i.e., embryo loss and early fetal loss) are year and season (García-Ispierto et al., 2006; Khan et al., 2013), parity number (Silke et al., 2002; Sartori et al., 2004; Lee and Kim, 2007; Bamber et al., 2009; El-Tarabany, 2016), BCS (Silke et al., 2002; Ribeiro et al., 2013; Trevisi, 2018), milk production (Silke et al., 2002; Diskin et al., 2006; Leroy et al., 2008), and clinical diseases (Perry et al., 2005; Celi et al., 2011; Mokhtari et al., 2016a; Ribeiro et al., 2016). Therefore, there is a need for studies specially designed to address the issue of LEL. The main objectives of this study were to assess the incidence of and risk factors for LEL in supplemented grazing dairy cows. An additional goal was to assess its association with reproductive performance. The hypotheses to test were that the incidence of LEL in supplemented grazing dairy cows is similar to that previously reported and that parity number, clinical diseases, low BCS, high milk yield (MY), and summer increase the odds for LEL.

\section{MATERIALS AND METHODS}

\section{Herd Management}

The study was carried out in a commercial dairy herd located in Carlos Casares, Province of Buenos Aires, Argentina $\left(35^{\circ} 37^{\prime} \mathrm{S}, 61^{\circ} 22^{\prime} \mathrm{W}\right)$, with a land base of 2,000 ha and approximately 2,600 Holstein dairy cows. Prepartum transition cows were kept on a dry lot and monitored for signs of calving by farm employees. Calving occurred year-round. Fresh cows were kept on a dry lot for $3 \mathrm{~d}$. Then, lactating cows were at pasture and supplemented with concentrates and silage. The total diet of lactating dairy cows consisted of $50 \%$ pasture, $25 \%$ concentrate, and $25 \%$ corn silage. Pastures consisted mainly of alfalfa and winter annual grasses (ryegrass). Cows grazed different paddocks in the morning and afternoon. Corn-based concentrate (60\% cornmeal and $40 \%$ soybean pellets) was equally fed 4 times per day, 2 times in the parlor during milking and 2 times mixed with corn silage. Corn silage was delivered twice per day in the paddocks. The average MY was $9,600 \mathrm{~kg}$ per lactation.

The voluntary waiting period was set at 50 DIM. All cows were detected on heat twice daily (during morning and afternoon milkings) and were artificially inseminated. Estrus detection was assisted by using tail painting. Cows were considered in estrus when more than $50 \%$ of tail paint was removed. An Ovsynch protocol was used for cows not bred within 70 DIM. Pregnancy diagnosis was performed by transrectal ultrasonography (US) at 28 to $42 \mathrm{~d}$ post-AI using a $7.5-\mathrm{MHz}$ linear transducer (Esaote Tringa Linear Vet, Pie Medical, Maastricht, the Netherland). Reconfirmation of pregnancy was performed by US at $90 \pm 7 \mathrm{~d}$ post-AI. Culling was mainly based on cow MY.

\section{Disease Definition}

All diseases were diagnosed by one of the authors (GD) with the exception of retained fetal membrane, clinical mastitis, and lameness, which were diagnosed by trained farm personnel. Retained fetal membrane was defined as when fetal membranes were not expelled by $24 \mathrm{~h}$ after calving (Kelton et al., 1998). Metritis was defined as cows having fetid vaginal discharge $<21$ DIM (Giuliodori et al., 2013a). Clinical endometritis was defined as the presence of pus in vaginal discharge $>21$ DIM (Sheldon et al., 2006). Pyometra was defined as the accumulation of purulent material within the uterine lumen in the presence of a persistent corpus luteum and a closed cervix (Sheldon et al., 2006). Clinical mastitis was defined as cows having abnormal milk secretion (e.g., clots, flakes, or watery secretion) from 1 or more quarters (Kelton et al., 1998). Clinical lameness was defined as cows having an episode of abnormal gait attributable to either the foot or the leg regardless of etiology or duration (Kelton et al., 1998). Finally, LEL was defined as when the embryo had no heartbeat or there was evidence of detached membranes or floating structures including embryo remnants by US (López-Gatius and García-Ispierto, 2010).

\section{Animal Selection and Study Design}

A data set with data for all the lactations started between January 1, 2011, and December 31, 2015 (13,551 cows), was extracted from commercial software (Dirsa S.A., Gonnet, Argentina) and used in this study. This study was approved by the Institutional Animal Care and Use Committee, Faculty of Veterinary Sciences, National University of La Plata, Argentina (code no. 66-2-17T).

Only lactations with valid reproductive and milk production data were eligible to be included in the study. 
Valid records were those having (1) a pregnancy diagnosis 28 to $42 \mathrm{~d}$ post-AI, (2) at least $1 \mathrm{BCS}<30 \mathrm{DIM}$ (BCS on a scale of 1 to 5; Ferguson et al., 1994), (3) at least $1 \mathrm{BCS} \pm 15 \mathrm{~d}$ relative to the date of pregnancyLEL diagnosis, and (4) at least 1 monthly milk check 30 to 45 d post-AI. Additionally, for lactations without a record of LEL, a pregnancy reconfirmation at $90 \pm 7$ $\mathrm{d}$ post-AI was required.

A retrospective case-control study was carried out to assess risk factors for LEL (Rothman et al., 2008). A case was defined as a cow diagnosed with LEL 28 to 42 d post-AI by transrectal US. A non-case was defined as a cow with positive pregnancy diagnosis 28 to 42 $\mathrm{d}$ post-AI by transrectal US that remained pregnant when rechecked at $90 \pm 7 \mathrm{~d}$ post-AI. This was done to exclude cows that had a pregnancy loss after being diagnosed pregnant at 28 to $42 \mathrm{~d}$ post-AI. In those cows with more than 1 event of LEL $(n=42)$ within the same lactation, only the first event was included in the study. A temporal matching ( $\pm 3 \mathrm{~d}$ around the date of the fecundating AI of the case) was used to randomly select 4 controls per case out of the available non-cases within each study year. Therefore, cases not accompanied by 4 controls were not included in the study.

\section{Descriptive Data}

The data set consisted of 13,551 records and had a total of 642 cases of LEL. Four cases of LEL were excluded because of failure with temporal matching (not accompanied by 4 controls) and 7 were excluded because they were diagnosed outside the time window (28-42 d post-AI). Therefore, 631 cases were included in the analysis together with 2,524 controls (out of 7,588 non-cases).

\section{Statistical Analysis}

The association of LEL (cases vs. controls) with MY was estimated with PROC GLIMMIX of SAS (SAS/ STAT version 9.4, SAS Institute Inc., Cary, NC) with normal distribution and identity link function adjusted by the quadratic effect of DIM (the mean when MY was measured was 148 DIM). The association of LEL with reproductive performance was assessed through calving to pregnancy interval, hazard of pregnancy, and odds for non-pregnancy. The calving to conception interval was estimated using PROC LIFETEST of SAS. The hazard of pregnancy was estimated with PROC PHREG of SAS. Finally, the odds for non-pregnancy were estimated with PROC GLIMMIX of SAS with binomial distribution and logit link function.

The risk for LEL was evaluated by logistic models with PROC GLIMMIX of SAS with binomial distri- bution and logit link function. Potential risk factors were first assessed as fixed effects in univariable models and then offered to multivariable models if $P<0.15$. Assessed risk factors were year of LEL (2011 through 2015), season of LEL (summer vs. fall vs. winter vs. spring), parity ( 1 vs. 2 vs. $\geq 3$ ), uterine disease (UD; yes vs. no; included retention of fetal membranes, metritis, clinical endometritis, and pyometra), non-uterine diseases (NUD; yes vs. no; included clinical mastitis and clinical lameness that occurred between AI and pregnancy diagnosis by US $28-42$ d post-AI), BCS at parturition (BCS-PAR; $<2.75$ vs. $2.75-3.25$ vs. $>3.25$ ), BCS at 28 to 42 d post-AI (BCS-LEL; $<2.50$ vs. $2.50-3.00$ vs. $>3.00$ ), and all first-order interactions. Also, DIM at LEL and MY were included as continuous predictors. Modeling in multivariable logistic models was performed using the manual backward elimination method with an exclusion criterion set at $P>0.1$. Statistical significance was set at $P<0.05$ and a tendency was set at $P \leq 0.10$.

\section{RESULTS}

\section{Descriptive Analysis}

In the data set $(\mathrm{n}=13,551)$, incidence of LEL, UD, and NUD was 4.7, 22.0, and $23.0 \%$, respectively. Cases conceived at similar DIM [median (top and bottom quartiles)] as controls [118 (75-204) and 118 (81-182), respectively], and the different cases experienced LEL on that gestation, whereas the controls did not.

\section{Association of LEL with MY and Reproductive Performance}

Cases tended to have higher MY than controls (32.5 \pm 0.36 vs. $31.8 \pm 0.17 \mathrm{~kg} ; P=0.10)$. Also, cases had longer calving to pregnancy interval [median (95\% CI); $226(208-238)$ vs. $118(115-122)$ d; $P<0.01$; Figure 1] and lower hazard of pregnancy than controls (hazard ratio $=0.385 ; 95 \% \mathrm{CI}=0.346-0.429 ; P<0.01)$. Finally, cases had higher odds for non-pregnancy than controls (odds ratio $=2.894 ; 95 \% \mathrm{CI}=2.368-3.536 ; P$ $<0.01$ ) given that the percentage of open cows was 26 $(164 / 631)$ and $11 \%(281 / 2,524)$ in cases and controls, respectively.

\section{Risk Factors for LEL}

The odds for LEL were not associated with year $(P=$ $0.99)$, season $(P=0.98)$, or BCS-PAR $(P=0.95$; Table $1)$. The odds for LEL were higher in cows in parity $\geq 3$ than in cows in parity $1(P<0.01$; Table 2$)$. The odds for LEL increased in cows with BCS-LEL $<2.50$ 


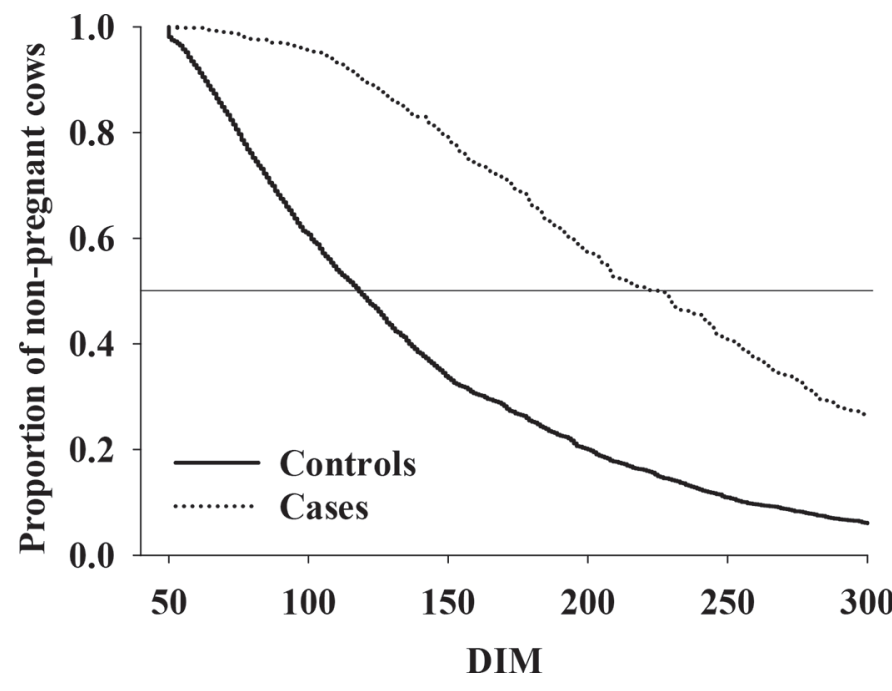

Figure 1. Calving to pregnancy interval in supplemented grazing dairy cows $(\mathrm{n}=3,155)$ from a commercial farm in Argentina experiencing late embryonic loss (LEL; cases, $\mathrm{n}=631$ ) or not (controls, $\mathrm{n}=$ $2,524)$. Cows with late embryonic loss had longer calving to pregnancy interval [median $(95 \% \mathrm{CI})]$ than herd mates $[226 \mathrm{~d}(208-238)$ vs. 118 d (115-122); $P<0.01]$. Cows with LEL had lower hazard of pregnancy than herd mates without LEL (hazard ratio $=0.385 ; 95 \%$ CI $=0.346-0.429 ; P<0.01)$. LEL was defined as when the embryo had no heartbeat or there was evidence of detached membranes or floating structures including embryo remnants by ultrasonography at 28 to 42 d post-AI. Cows with no LEL (controls) were defined as cows with a positive pregnancy diagnosis performed by ultrasonography at 28 to $42 \mathrm{~d}$ post-AI and reconfirmed as pregnant at $90 \pm 7 \mathrm{~d}$ post-AI. Four controls per case were randomly selected with temporal matching $( \pm 3$ $\mathrm{d}$ around the date of the fecundating AI of the case).

and decreased in cows with BCS-LEL $>3.0(P<0.01$; Table 2). The odds for LEL were not associated with UD, NUD, DIM, and MY in the multivariable model (Table 2) even though these variables were associated with the risk in univariable models (Table 1). Finally, all first-order interactions had $P>0.1$.

\section{DISCUSSION}

\section{Incidence of LEL}

Our results showed that $4.7 \%$ of cows had LEL between 28 and $42 \mathrm{~d}$ post-AI. Our finding is similar to that reported by Silke et al. (2002), who found a rate of $3.2 \%$ by using US in the same period ( $28-42 \mathrm{~d}$ post-AI). Santos et al. (2009) detected a decrease of 5.2 percentage points in conception rate from $38.3 \%$ on d 30 postservice to $33.1 \% 28 \mathrm{~d}$ later because of LEL and early fetal loss. Other authors have detected pregnancy losses of $22 \%$ by US between 30 and $70 \mathrm{~d}$ post-AI (Abdalla et al., 2017) and of $16.3 \%$ by using blood progesterone concentration between 30 and 60 d post-AI (Gábor et al., 2008). Differences in study design such as the timing of the diagnosis and assessed time window (28-42,
Table 1. Univariable logistic models assessing risk factors for late embryonic $\operatorname{loss}^{1}$ (LEL) in supplemented grazing dairy cows $(\mathrm{n}=3,155)$ from a commercial farm in Argentina

\begin{tabular}{|c|c|c|c|}
\hline Item & $\mathrm{OR}^{2}$ & $95 \% \mathrm{CI}$ & $P$-value \\
\hline \multicolumn{4}{|c|}{ Year of LEL } \\
\hline 2011 & Referent & & 0.99 \\
\hline 2012 & 0.965 & $0.689-1.352$ & \\
\hline 2013 & 0.984 & $0.715-1.354$ & \\
\hline 2014 & 0.992 & $0.717-1.371$ & \\
\hline 2015 & 0.958 & $0.688-1.335$ & \\
\hline \multicolumn{4}{|c|}{ Season of LEL } \\
\hline Summer & Referent & & 0.98 \\
\hline Fall & 1.036 & $0.815-1.317$ & \\
\hline Winter & 1.039 & $0.817-1.323$ & \\
\hline Spring & 1.054 & $0.807-1.377$ & \\
\hline \multicolumn{4}{|l|}{ Parity } \\
\hline 1 & Referent & & $<0.01$ \\
\hline 2 & 1.505 & $1.188-1.907$ & \\
\hline \multirow{2}{*}{\multicolumn{4}{|c|}{ BCS-PAR ${ }^{3}$}} \\
\hline & & & \\
\hline $2.75-3.25$ & Referent & & 0.95 \\
\hline$<2.75$ & 1.032 & $0.837-1.273$ & \\
\hline$>3.25$ & 1.037 & $0.754-1.427$ & \\
\hline \multicolumn{4}{|l|}{ BCS-LEL $^{4}$} \\
\hline $2.50-3.00$ & Referent & & $<0.01$ \\
\hline$<2.50$ & 2.016 & $1.488-2.731$ & \\
\hline$>3.00$ & 0.821 & $0.631-1.069$ & \\
\hline \multicolumn{4}{|l|}{$\mathrm{UD}^{5}$} \\
\hline No & Referent & & 0.04 \\
\hline Yes & 1.225 & $1.010-1.487$ & \\
\hline \multicolumn{4}{|l|}{ NUD $^{6}$} \\
\hline No & Referent & & 0.04 \\
\hline Yes & 1.246 & $1.011-1.535$ & \\
\hline DIM $^{7}$ & 1.025 & $1.004-1.046$ & 0.02 \\
\hline Daily $\mathrm{MY}^{8}$ & 1.136 & $1.036-1.246$ & 0.01 \\
\hline
\end{tabular}

${ }^{1}$ Defined as when the embryo had no heartbeat or there was evidence of detached membranes or floating structures including embryo remnants by ultrasonography at 28 to $42 \mathrm{~d}$ post-AI.

${ }^{2}$ Odds ratio for LEL.

${ }^{3} \mathrm{BCS}$ (5-point scale) during the first 30 DIM.

${ }^{4} \mathrm{BCS}$ (5-point scale) $30 \mathrm{~d}$ before the diagnosis of pregnancy or LEL.

${ }^{5}$ Uterine disease detected postpartum (i.e., retained fetal membranes, metritis, clinical endometritis, and pyometra).

${ }^{6}$ Non-uterine disease (i.e., clinical mastitis and clinical lameness) diagnosed between AI and diagnosis of pregnancy or LEL.

${ }^{7} \mathrm{DIM}$ at the diagnosis of pregnancy or LEL (performed 28-42 d postAI). Odds are expressed as the increment of $21 \mathrm{~d}$ over the mean (148 d).

${ }^{8}$ Daily milk yield in the last monthly milk check before the diagnosis of pregnancy or LEL (performed 28-42 d post-AI). Odds are expressed as the increment of $1 \mathrm{SD}(8.49 \mathrm{~kg})$ over the mean $(32.04 \mathrm{~kg} / \mathrm{d})$. This association was controlled by DIM and DIM $\times$ DIM.

$30-58$, or even 30 up to $84 \mathrm{~d}$ post-AI) and diagnostic tool used (US vs. progesterone measurement) make comparison among different studies difficult.

\section{Association of LEL with Reproductive Performance}

Cows that had an LEL event conceived 108 d later than the control cows, which was further delayed if we compare that increment with the delay associated with metritis (20 d; Giuliodori et al., 2013a), clinical 
endometritis (30-70 d; Plöntzke et al., 2011; Giuliodori et al., 2013b, 2017), or subclinical endometritis (30 d; Madoz et al., 2013). With LEL, it is necessary to get the cows pregnant twice in the same lactation.

\section{Risk Factors for LEL}

We found that the odds for LEL were associated with parity and BCS-LEL, supporting the proposed hypothesis that the odds for LEL increase with parity number and low BCS. Our finding that parity was associated with the odds for LEL is in agreement with previous reports (Lee and Kim, 2007; El-Tarabany, 2016). However, other studies have failed to find this association (Silke et al., 2002; Bamber et al., 2009). A possible explanation could be that multiparous cows have lower plasma progesterone and estradiol concentrations than primiparous cows (Sartori et al., 2004; Borchardt et al., 2017), which could be associated with higher odds for LEL.

Our results showed that BCS-LEL (but not BCSPAR) was also associated with the odds for LEL. Our result is in agreement with Ribeiro et al. (2016), who found that low BCS at AI was negatively associated with pregnancy on d 32 post-AI. In addition, Silke et

Table 2. Final multivariable logistic model assessing risk factors for late embryonic $\operatorname{loss}^{1}$ (LEL) in supplemented grazing dairy cows $(\mathrm{n}=$ $3,155)$ from a commercial farm in Argentina ${ }^{2}$

\begin{tabular}{llll}
\hline Item & $\mathrm{OR}^{3}$ & $95 \% \mathrm{CI}$ & $P$-value \\
\hline Parity & & & \\
1 & 1 & & $<0.01$ \\
2 & 1.531 & $1.207-1.942$ & \\
$\geq 3$ & 2.475 & $1.991-3.076$ & \\
BCS-LEL & & & $<0.01$ \\
$2.50-3.00$ & 1 & & \\
$<2.50$ & 1.811 & $1.329-2.467$ & \\
$>3.00$ & 0.695 & $0.531-0.910$ & \\
\hline
\end{tabular}

${ }^{1}$ Defined as when the embryo had no heartbeat or there was evidence of detached membranes or floating structures including embryo remnants by ultrasonography at 28 to $42 \mathrm{~d}$ post-AI.

${ }^{2}$ Predictors offered to the multivariable model were parity, BCS-LEL, uterine disease, non-uterine disease, DIM, daily milk yield, and firstorder interactions. Uterine disease (i.e., retained fetal membranes, metritis, clinical endometritis, and pyometra) was removed from the multivariable model (odds ratio, $\mathrm{OR}=1.090 ; 95 \% \mathrm{CI}=0.886-1.341$; $P=0.42$; not shown) and from Table 2 . Non-uterine disease (i.e., clinical mastitis and clinical lameness) diagnosed between AI and diagnosis of pregnancy or LEL was removed from the multivariable model (OR $=1.129 ; 95 \% \mathrm{CI}=0.913-1.398 ; P=0.26)$ and from Table 2 . DIM (28-42 d post-AI; mean of $148 \mathrm{DIM})$ was removed from the multivariable model $(\mathrm{OR}=1.009 ; 95 \% \mathrm{CI}=0.988-1.030 ; P=0.32)$ and from Table 2. Daily milk yield in the last monthly milk check before the diagnosis of pregnancy or LEL, performed 28 to $42 \mathrm{~d}$ post-AI (mean of $148 \mathrm{DIM})$, was removed from the multivariable model $(\mathrm{OR}=0.960$; $95 \%$ CI $=0.863-1.069 ; P=0.46)$ and from Table 2 . All first-order interactions had $P>0.1$.

${ }^{3}$ Odds ratio for LEL.

${ }^{4} \mathrm{BCS}$ (5-point scale) $30 \mathrm{~d}$ before the diagnosis of pregnancy or LEL. al. (2002) found that cows that lost BCS had a higher proportion of LEL than herd mates that kept or gained BCS postpartum. Conversely, Mokhtari et al. (2016b) and Silke et al. (2002) failed to find this association. A possible explanation for the link between low BCS and the risk for LEL could be through lipolysis, which leads to high nonesterified fatty acid (NEFA) concentration. During the past several decades, many direct toxic effects of NEFA have been demonstrated on many cells such as granulosa cells (Vanholder et al., 2005), oocytes (Leroy et al., 2011), and developing embryos (Leroy et al., 2010). In addition, high NEFA concentration could lead to insulin resistance, decreasing the sensitivity of the ovary to LH and FSH (Lucy, 2007).

We found that the odds for LEL were not associated with UD and NUD. This finding is in agreement with Mokhtari et al. (2016b), who did not find any association between UD and embryo and fetal loss 30 to 68 d post-AI. Conversely, Ribeiro et al. (2016) reported higher embryonic and fetal loss $(8.9 \%$ more $)$ in cows with clinical diseases, and others found that clinical mastitis and clinical lameness are associated with increased risk for fetal death (Risco et al., 1999; Santos et al., 2004; Alawneh et al., 2011). We also found that MY was not associated with the odds for LEL, which agrees with Silke et al. (2002) and Diskin et al. (2006), who did not find any association between MY or milk energy output by 120 DIM and embryonic loss. Conversely, Wiltbank et al. (2001) reported that highproducing cows had a higher risk for embryonic or fetal death. Finally, we found no association between year and season with the odds for LEL. Conversely, other studies have reported that embryonic loss 21 to $30 \mathrm{~d}$ post-AI is associated with high temperature-humidity index (García-Ispierto et al., 2006) and that implantation failure in early pregnancy is associated with heat stress during summer (Khan et al., 2013).

One of the main strengths of the study is that this is the first case-control study assessing risk factors for LEL, whereas previous studies are cohort studies. Rothman et al. (2008) stated that case-control studies are a more efficient version of corresponding cohort studies to assess risk factors when a low proportion of the population is affected (Rothman et al., 2008). Another strength is that it involves a high number of cases of LEL that were directly detected in situ by US at the time of pregnancy check (i.e., the embryo was dying or recently dead), whereas previous studies were run on smaller data sets and most of them diagnosed the loss at pregnancy reconfirmation. A final strength is that it reports data about LEL in highly supplemented grazing dairy cows, whereas previous studies mostly involved confined cows, and only 1 included fully grazed cows. The main limitations are that (1) it is very likely that 
the incidence of LEL is underestimated because cows were assessed for LEL only once between 28 and $42 \mathrm{~d}$ post-AI with a time window of $3 \mathrm{~d}$ where the dead embryo could be seen by US, (2) it is very likely that the association between disease and odds for LEL is underestimated because subclinical diseases (i.e., subclinical endometritis, subclinical mastitis, subclinical lameness) were not included, and (3) this case-control study was carried out in only 1 commercial dairy farm.

\section{CONCLUSIONS}

The odds for LEL are higher in multiparous cows and in cows with low BCS compared with their counterparts. We also conclude that LEL is negatively associated with reproductive performance given that cows that experience LEL must get pregnant a second time in the same lactation, thus extending the calving to pregnancy by $108 \mathrm{~d}$.

\section{ACKNOWLEDGMENTS}

This study and the L. E. Quintero Rodriguez fellowship were financed by the Argentinean Ministry of Science, Technology and Productive Innovation (MINCyT), Ciudad Autónoma de Buenos Aires, C1425FQD, Argentina, through a Research Project in Science and Technology (PICT 2013-3260) given to R. L. de la Sota and M. J. Giuliodori, and by National University of La Plata (UNLP), La Plata, B1900, Argentina, through an Incentive Project (V11/230) given to R. L. de la Sota.

\section{REFERENCES}

Abdalla, H., A. Elghafghuf, I. Elsohaby, and M. Nasr. 2017. Maternal and non-maternal factors associated with late embryonic and early fetal losses in dairy cows. Theriogenology 100:16-23.

Alawneh, J. I., R. A. Laven, and M. A. Stevenson. 2011. The effect of lameness on the fertility of dairy cattle in a seasonally breeding pasture-based system. J. Dairy Sci. 94:5487-5493.

Bamber, R. L., G. E. Shook, M. C. Wiltbank, J. E. P. Santos, and P. M. Fricke. 2009. Genetic parameters for anovulation and pregnancy loss in dairy cattle. J. Dairy Sci. 92:5739-5753.

Borchardt, S., P. Haimerl, A. Pohl, and W. Heuwieser. 2017. Evaluation of prostaglandin $\mathrm{F}_{2 \alpha}$ versus prostaglandin $\mathrm{F}_{2 \alpha}$ plus gonadotropin-releasing hormone as Presynch methods preceding an Ovsynch in lactating dairy cows: A meta-analysis. J. Dairy Sci. 100:4065-4077.

Celi, P., M. Merlo, L. Da Dalt, A. Stefani, O. Barbato, and G. Gabai. 2011. Relationship between late embryonic mortality and the increase in plasma advanced oxidised protein products (AOPP) in dairy cows. Reprod. Fertil. Dev. 23:527-533.

De Vries, A. 2006. Economic value of pregnancy in dairy cattle. J. Dairy Sci. 89:3876-3885.

Diskin, M. G., J. J. Murphy, and J. M. Sreenan. 2006. Embryo survival in dairy cows managed under pastoral conditions. Anim. Reprod. Sci. 96:297-311.

El-Tarabany, M. S. 2016. The efficiency of new CIDR and once-used CIDR to synchronize ovulation in primiparous and multiparous Holstein cows. Anim. Reprod. Sci. 173:29-34.
Engelke, J., H. Knaack, M. Linden, M. Feldmann, N. Gundling, and Y. Gundelach. 2015. Identification of embryonic/fetal mortality in cows by semi-quantitative detection of pregnancy-associated glycoproteins. Livest. Sci. 178:363-370.

Evans, A. C. O., and S. W. Walsh. 2011. The physiology of multifactorial problems limiting the establishment of pregnancy in dairy cattle. Reprod. Fertil. Dev. 24:233-237.

Ferguson, J. D., D. T. Galligan, and N. Thomsen. 1994. Principal descriptors of body condition score in Holstein cows. J. Dairy Sci. 77:2695-2703.

Gábor, G., F. Tóth, L. Ózsvári, Z. Abonyi-Tóth, and R. G. Sasser. 2008. Factors influencing pregnancy rate and late embryonic loss in dairy cattle. Reprod. Domest. Anim. 43:53-58.

García-Ispierto, I., F. López-Gatius, P. Santolaria, J. L. Yániz, C. Nogareda, M. López-Béjar, and F. De Rensis. 2006. Relationship between heat stress during the peri-implantation period and early fetal loss in dairy cattle. Theriogenology 65:799-807.

Giuliodori, M. J., M. Magnasco, R. P. Magnasco, I. M. Lacau-Mengido, and R. L. de la Sota. 2017. Purulent vaginal discharge in grazing dairy cows: Risk factors, reproductive performance, and prostaglandin $\mathrm{F}_{2 \alpha}$ treatment. J. Dairy Sci. 100:3805-3815.

Giuliodori, M. J., R. P. Magnasco, D. Becu-Villalobos, I. M. LacauMengido, C. A. Risco, and R. L. de la Sota. 2013a. Metritis in dairy cows: Risk factors and reproductive performance. J. Dairy Sci. 96:3621-3631.

Giuliodori, M. J., R. P. Magnasco, D. Becu-Villalobos, I. M. LacauMengido, C. A. Risco, and R. L. de la Sota. 2013b. Clinical endometritis in an Argentinean herd of dairy cows: Risk factors and reproductive efficiency. J. Dairy Sci. 96:210-218.

Kelton, D. F., K. D. Lissemore, and R. E. Martin. 1998. Recommendations for recording and calculating the incidence of selected clinical diseases of dairy cattle. J. Dairy Sci. 81:2502-2509.

Khan, F. A., S. Prasad, and H. P. Gupta. 2013. Effect of heat stress on pregnancy rates of crossbred dairy cattle in Terai region of Uttarakhand, India. Asian Pac. J. Reprod. 2:277-279.

Lee, J. I., and I. Kim. 2007. Pregnancy loss in dairy cows: The contributing factors, the effects on reproductive performance and the economic impact. J. Vet. Sci. 8:283-288.

Leroy, J. L. M. R., D. B. Rizos, R. C. Sturmey, and P. A. Bossaert. 2011. Intrafollicular conditions as a major link between maternal metabolism and oocyte quality: A focus on dairy cow fertility. Reprod. Fertil. Dev. 24:1-12.

Leroy, J. L. M. R., V. Van Hoeck, M. Clemente, D. Rizos, A. Van Soom, M. Uytterhoeven, and P. E. J. Bols. 2010. The effect of nutritionally induced hyperlipidaemia on in vitro bovine embryo quality. Hum. Reprod. 25:768-778.

Leroy, J. L. M. R., A. Van Soom, G. Opsomer, and P. E. J. Bols. 2008. The consequences of metabolic changes in high-yielding dairy cows on oocyte and embryo quality. Animal 2:1120-1127.

López-Gatius, F., and I. García-Ispierto. 2010. Ultrasound and endocrine findings that help to assess the risk of late embryo/early foetal loss by non-infectious cause in dairy cattle. Reprod. Domest. Anim. 45:15-24.

Lucy, M. C. 2007. Fertility in high-producing dairy cows: Reasons for decline and corrective strategies for sustainable improvement. Soc. Reprod. Fertil. Suppl. 64:237-254.

Madoz, L. V., M. J. Giuliodori, M. Jaureguiberry, J. Plöntzke, M. Drillich, and R. L. de la Sota. 2013. The relationship between endometrial cytology during estrous cycle and cutoff points for the diagnosis of subclinical endometritis in grazing dairy cows. J. Dairy Sci. 96:4333-4339.

Mokhtari, A., M. Kafi, M. J. Zamiri, and R. Akbari. 2016a. Factors affecting the size of ovulatory follicles and conception rate in highyielding dairy cows. Theriogenology 85:747-753.

Mokhtari, A., M. Kafi, M. J. Zamiri, and R. Akbari. 2016b. Factors affecting the size of ovulatory follicles and conception rate in highyielding dairy cows. Theriogenology 85:747-753.

Perry, G. A., M. F. Smith, M. C. Lucy, J. A. Green, T. E. Parks, M. D. MacNeil, A. J. Roberts, and T. W. Geary. 2005. Relationship between follicle size at insemination and pregnancy success. Proc. Natl. Acad. Sci. USA 102:5268-5273. 
Plöntzke, J., L. V. Madoz, R. L. De la Sota, W. Heuwieser, and M. Drillich. 2011. Prevalence of clinical endometritis and its impact on reproductive performance in grazing dairy cattle in Argentina. Reprod. Domest. Anim. 46:520-526.

Ribeiro, E. S., G. Gomes, L. F. Greco, R. L. A. Cerri, A. Vieira-Neto, P. L. J. Monteiro, F. S. Lima, R. S. Bisinotto, W. W. Thatcher, and J. E. P. Santos. 2016. Carryover effect of postpartum inflammatory diseases on developmental biology and fertility in lactating dairy cows. J. Dairy Sci. 99:2201-2220.

Ribeiro, E. S., F. S. Lima, L. F. Greco, R. S. Bisinotto, A. P. A. Monteiro, M. Favoreto, H. Ayres, R. S. Marsola, N. Martinez, W. W. Thatcher, and J. E. P. Santos. 2013. Prevalence of periparturient diseases and effects on fertility of seasonally calving grazing dairy cows supplemented with concentrates. J. Dairy Sci. 96:5682-5697.

Risco, C. A., G. A. Donovan, and J. Hernandez. 1999. Clinical mastitis associated with abortion in dairy cows. J. Dairy Sci. 82:1684-1689.

Rothman, K. J., S. Greenland, and T. L. Lash. 2008. Case-control studies. Pages 111-147 in Modern Epidemiology. 3rd ed. K. J. Rothman, S. Greenland, and T. L. Lash, ed. Lippincott Williams and Wilkins, Philadelphia, PA.

Santos, J. E. P., H. M. Rutigliano, and M. F. S. Filho. 2009. Risk factors for resumption of |postpartum estrous cycles and embryonic survival in lactating dairy cows. Anim. Reprod. Sci. 110:207-221.

Santos, J. E. P., W. W. Thatcher, R. C. Chebel, R. L. A. Cerri, and K. N. Galvão. 2004. The effect of embryonic death rates in cattle on the efficacy of estrus synchronization programs. Anim. Reprod. Sci. 82-83:513-535.
Sartori, R., J. M. Haughian, R. D. Shaver, G. J. M. Rosa, and M. C. Wiltbank. 2004. Comparison of ovarian function and circulating steroids in estrous cycles of Holstein heifers and lactating cows. J. Dairy Sci. 87:905-920.

Sheldon, I. M., G. S. Lewis, S. LeBlanc, and R. O. Gilbert. 2006. Defining postpartum uterine disease in cattle. Theriogenology 65:1516-1530.

Silke, V., M. G. Diskin, D. A. Kenny, M. P. Boland, J. F. Mee, and J. M. Sreenan. 2002. Extent, pattern and factors associated with late embryonic loss in dairy cows. Anim. Reprod. Sci. 71:1-12.

Trevisi, E. 2018. Research in veterinary science assessment of the innate immune response in the periparturient cow oxidative stress days from parturition. Res. Vet. Sci. 116:47-54.

Vanholder, T., J. L. M. R. Leroy, A. Van Soom, G. Opsomer, D. Maes, M. Coryn, and A. De Kruif. 2005. Effect of non-esterified fatty acids on bovine granulosa cell steroidogenesis and proliferation in vitro. Anim. Reprod. Sci. 87:33-44.

Wiltbank, M. C. G. M. Baez, A. Garcia-Guerra, M. Z. Toledo, P. L. J. Monteiro, L. F. Melo, J. C. Ochoa, J. E. P. Santos, and R. Sartori. 2016. Pivotal periods for pregnancy loss during the first trimester of gestation in lactating dairy cows. Theriogenology 86:239-253.

Wiltbank, M. C., R. Sartori, S. Sangsritavong, H. Lopez, J. M. Haughian, P. M. Fricke, and A. Gumen. 2001. Novel effects of nutrition on reproduction in lactating dairy cows. J. Dairy Sci. 84(Suppl.):32. (Abstr.) 